\title{
Sex differences in the incidence of cerebrovascular disease
}

\author{
S. HABERMAN
}

From the Actuarial Science Unit, City University, London

RUDY CAPILDEO AND F. CLIFFORD ROSE

From the Department of Neurology, Charing Cross Hospital, London

SUMMARY Incidence rates for cerebrovascular disease reported by community-based and hospital-based studies during the past 15 years are analysed. The range of variation between areas is wide, with Japan and Finland experiencing the highest age-adjusted rates. Of 16 studies reporting incidence rates by sex, 15 showed a male excess, and nine of these were significant when the incidence rate was age-adjusted. Overall, the excess is about $30 \%$ for both community-based and hospital-based studies. For cerebral infarction the excess is about $45 \%$. Intracerebral haemorrhage shows little difference between the two sexes and subarachnoid haemorrhage shows a male deficit of about $50 \%$. These findings are self-consistent.

We review here all studies that have reported incidence rates of cerebrovascular disease with particular reference to differences between the two sexes. ${ }^{1-27}$ The main sources of these data are from community-based and hospital-based longitudinal studies of the disease.

The variation of incidence rates with age is well-documented for all cerebrovascular disease and for the principal diagnostic subdivisions. ${ }^{28}{ }^{29}$ Work is in hand to represent this age variation formally by mathematical curves.

The results discussed in this review are concerned with the variation in incidence rates by sex. A broader discussion of sex differences in stroke, embracing national cause-of-death mortality rates and survival rates after the onset of stroke, is in the course of being published. ${ }^{30}$

\section{Method}

To compare age- and sex-specific incidence rates in different epidemiological studies may involve the comparison of a large quantity of data. However, with a condition like cerebrovascular disease, which has a low crude incidence rate, such a procedure could involve calculating specific rates based on few person-years of exposure, and hence it could be subject to considerable statistical fluctuation. Comparison between studies is also hindered by the different methods of age grouping used. Therefore there are advantages in using a single-figure index to summarise and compare studies, accepting that some statistical information is likely to be lost in this process.

The use of crude indices has disadvantages. These problems can be reduced by age-standardisation procedures when both numerator and denominator data are available for all strata in each population; when the aim is primarily descriptive, the usual approach is by direct standardisation. The England and Wales home population for both sexes for 1973 has been used as the standard. ${ }^{31}$

Since the level of annual incidence is approximately $2-3$ per 1000 , the number of new cases in any single investigation is likely to be small, so that estimates of incidence rates should be qualified by confidence limits. Following the suggestion of Lew, ${ }^{32}$ it is assumed that the number of new cases follows a Poisson distribution, and corresponding formulae for approximate $95 \%$ confidence limits for age-adjusted incidence rates are given in the Appendix.

To test the significance of the difference between two age-adjusted incidence rates, a method proposed by Armitage, ${ }^{33}$ based on Cochran, ${ }^{34}$ has been used, and the formulae are presented in the Appendix.

Both direct and indirect methods of standardisation have attracted criticism in the literature $\mathrm{s}^{35}$ on the grounds that they place too much 
weight on absolute rather than relative differences, and hence, in this context, that the indices respond more to differences at the oldest ages than at the youngest. Such criticisms are not crucial when, as with cerebrovascular disease, the age-specific rates are negligible at ages under 45 .

\section{Results}

The community-based studies reported in the last 15 years are summarised in Table 1 giving age-adjusted incidence rates (adjusted to the England and Wales 1973 population) and approximate confidence intervals.

Table 1 Age-adjusted incidence rates for all cerebrovascular disease (in 100000 a year) from different community-based studies, for both sexes of all races

\begin{tabular}{|c|c|c|c|c|}
\hline Study & $\begin{array}{l}\text { Years } \\
\text { covered }\end{array}$ & No. of cases & $\begin{array}{l}\text { Age- } \\
\text { adjusted } \\
\text { rates }\end{array}$ & $\begin{array}{l}95 \% \\
\text { confidence } \\
\text { interval }\end{array}$ \\
\hline Rochester, USA ${ }^{1}$ & $1945-54$ & $\begin{array}{l}584 \\
\text { (whites only) }\end{array}$ & 284 & \pm 24 \\
\hline Rochester, USA ${ }^{2}$ & $1955-69$ & $\begin{array}{l}993 \\
\text { (whites only) }\end{array}$ & 236 & \pm 15 \\
\hline Middlesex Co, USA ${ }^{3}$ & $1957-58$ & $\begin{array}{l}191 \\
\text { (whites only) }\end{array}$ & 277 & \pm 39 \\
\hline Evans Co, USA & $1960-69$ & 94 & 303 & \pm 34 \\
\hline Fargo Moorhead, USA ${ }^{\mathbf{s}}$ & $1965-66$ & 408 & 355 & \pm 22 \\
\hline Mid-Missouri, USA ${ }^{6}$ & $1965-66$ & $\begin{array}{l}195 \\
\text { (whites only) }\end{array}$ & 278 & \pm 40 \\
\hline Mid-Missouri, USA ${ }^{7}$ & $1966-67$ & 189 & 228 & \pm 35 \\
\hline W. Pennsylvania, USA ${ }^{8}$ & 1968 & 774 & 437 & - \\
\hline Oxford, UK ${ }^{9}$ & $1963-64$ & 630 & 222 & \pm 27 \\
\hline \multicolumn{5}{|l|}{ Farnham and Frimley, } \\
\hline $\mathbf{U K}^{10}$ & $1971-72$ & 380 & 191 & - \\
\hline Carlisle, UK ${ }^{11}$ & 1978 & 251 & 230 & \pm 29 \\
\hline Frederiskberg, Denmark ${ }^{12}$ & $1971-73$ & 556 & 180 & \pm 15 \\
\hline Dublin, Ireland $^{13}$ & $1972-74$ & 543 & 249 & \pm 33 \\
\hline Espoo, Finland ${ }^{14}$ & 1972 & 153 & 332 & \pm 58 \\
\hline Tartu, USSR ${ }^{15}$ & $1970-73$ & 667 & 231 & \pm 18 \\
\hline Hiroshima, Japan ${ }^{16}$ & $1963-64$ & 175 & 518 & \pm 28 \\
\hline
\end{tabular}

Within the United States of America the range of variation is 1.92 , measured by the ratio between the extreme levels. The weighted average age-adjusted incidence rate for the USA is 310 per 100000 a year (using weights proportional to the number of cases in each study). Within Europe, the range of variation similarly calculated is $1 \cdot 84$, and the weighted average age-adjusted incidence rate is 223 per 100000 a year.

The hospital-based studies reported in the last 25 years are summarised in Table 2 with age-adjusted incidence rates, as in Table 1 . The variation is again wide and significant.

The data in Tables 1 and 2 are based on all new cases of cerebrovascular disease with the different types of pathology considered together. In some reports no attempt was made to distinguish between them, but where such attempts were made the criteria often differed between studies. Table 3 gives the
Table 2 Age-adjusted incidence rates for all cerebrovascular disease (in 100000 a year) from different hospital-based studies, for both sexes of all races

\begin{tabular}{|c|c|c|c|c|}
\hline Study & $\begin{array}{l}\text { Years } \\
\text { covered }\end{array}$ & No. of cases & $\begin{array}{l}\text { Age- } \\
\text { adjusted } \\
\text { rates }\end{array}$ & $\begin{array}{l}95 \% \\
\text { confidence } \\
\text { interval }\end{array}$ \\
\hline Harlem, USA $^{17}$ & 1971 & $\begin{array}{c}328 \text { (non- } \\
\text { whites only) }\end{array}$ & 228 & - \\
\hline Monroe Co, USA ${ }^{18}$ & 1971 & 383 & 214 & \pm 13 \\
\hline Manitoba, Canada ${ }^{19}$ & $1970-71$ & 1367 & 199 & \pm 12 \\
\hline Carlisle, UK ${ }^{20}$ & $1955-61$ & 694 & 157 & \pm 12 \\
\hline Frederiksberg, Denmark ${ }^{21}$ & $1940-53$ & 1000 & 76 & \pm 18 \\
\hline 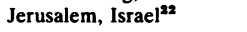 & $1960-67$ & 1517 & 170 & \pm 9 \\
\hline
\end{tabular}

Table 3 Age-adjusted incidence rates for cerebral infarction (in 100000 a year) from different community-based studies, for both sexes

\begin{tabular}{|c|c|c|c|c|}
\hline Study & $\begin{array}{l}\text { Years } \\
\text { covered }\end{array}$ & No. of cases & $\begin{array}{l}\text { Age- } \\
\text { adjusted } \\
\text { rates }\end{array}$ & $\begin{array}{l}95 \% \\
\text { confidence } \\
\text { interval }\end{array}$ \\
\hline Rochester, USA ${ }^{2}$ & $1945-54$ & 428 & 218 & \pm 21 \\
\hline Rochester, USA ${ }^{2}$ & $1955-69$ & 777 & 186 & \pm 13 \\
\hline Middlesex Co, USA ${ }^{8}$ & $1957-58$ & 91 & 131 & \pm 27 \\
\hline Framingham, USA ${ }^{23}$ & $1950-72$ & 174 & $102^{*}$ & - \\
\hline Oxford, UK ${ }^{9}$ & $1963-64$ & 251 & 90 & \pm 11 \\
\hline Frederiksberg, Denmark ${ }^{12}$ & $1971-73$ & 164 & 57 & \pm 9 \\
\hline Tartu, USSR ${ }^{15}$ & $1970-73$ & 532 & 185 & \pm 16 \\
\hline Hisayama, Japan ${ }^{24}$ & $1961-65$ & 32 & 364 & - \\
\hline Hiroshima, Japan ${ }^{16}$ & $1958-64$ & 80 & 261 & \pm 64 \\
\hline
\end{tabular}

*Based on ages under 85

age-adjusted incidence rates for community-based studies of cerebral infarction.

The range of variation between these rates is wide and statistically significant. The weighted average age-adjusted incidence rates for cerebral infarction for the three principal geographical regions studied were:

$$
\begin{array}{ll}
\text { USA } & 193 \text { (per } 100000 \text { a year) } \\
\text { Japan } & 290 \text { (per } 100000 \text { a year) } \\
\text { Europe } & 138 \text { (per } 100000 \text { a year) }
\end{array}
$$

Tables 4 and 5 present the age-adjusted incidence rates for cerebrovascular disease in the two sexes in several studies.

The significance of the difference between each pair is tested using a method due to Cochran..$^{33}{ }^{34} \mathrm{All}$ but one of the comparisons between male and female rates are greater than 1 in Table 4 and all are greater than 1 in Table 5. This apparent male excess is significant in six out of 13 possible comparisons from Table 4, and three out of three in Table 5. The weighted average age-adjusted incidence rates show a male excess of $29 \%$ in Table 4 and $26 \%$ in Table 5 .

Table 6 shows comparisons of male and female incidence rates for cerebral infarction. In all seven studies there is a male excess, which is significant for five of the six comparisons. The weighted average age-adjusted incidence rates show a male excess of $46 \%$. 
Table 4 Sex differences in age-adjusted incidence rates for cerebrovascular disease (in 100000 a year) from different community-based studies

\begin{tabular}{|c|c|c|c|c|}
\hline Study & Male rate & Female rate & $S D^{*}$ & $\begin{array}{l}\text { Malel } \\
\text { Female }\end{array}$ \\
\hline \multicolumn{5}{|l|}{ Evans County, USA } \\
\hline Whites & 402 & 150 & $\mathrm{p}<0.005$ & 2.68 \\
\hline Non-whites & 401 & 429 & $p>0.05$ & 0.93 \\
\hline \multicolumn{5}{|l|}{ Rochester, USA } \\
\hline $1955-69$ & 322 & 194 & $\mathrm{p}<0.00005$ & 1.66 \\
\hline Middlesex, Co, USA & 300 & 254 & $p>0.05$ & $1 \cdot 18$ \\
\hline Fargo Moorhead, USA & 369 & 344 & $\mathrm{p}>0.05$ & 1.07 \\
\hline \multicolumn{5}{|l|}{$\begin{array}{l}\text { Mid-Missouri, USA } \\
\text { 1966-67 }\end{array}$} \\
\hline Whites & 255 & 215 & $p>0.05$ & $1 \cdot 19$ \\
\hline Non-whites & 656 & 367 & $p>0.05$ & 1.79 \\
\hline \multicolumn{5}{|l|}{ Jefferson Co, USA ${ }^{25}$} \\
\hline Whites & 245 & 124 & - & 1.98 \\
\hline Non-whites & 359 & 344 & - & 1.04 \\
\hline Oxford, UK & 228 & 219 & $p>0.05$ & 1.04 \\
\hline Farnham and Frimley, UK & 212 & 175 & - & $1 \cdot 21$ \\
\hline Frederiksberg, Denmark & 221 & 154 & $p<0.0005$ & 1.44 \\
\hline Dublin, Ireland & 274 & 231 & $\mathrm{p}<0.05$ & $1 \cdot 19$ \\
\hline Espoo, Finland & 364 & 305 & $p>0.05$ & $1 \cdot 19$ \\
\hline Tartu, USSR & 274 & 208 & $p<0.001$ & $1 \cdot 32$ \\
\hline Hiroshima, Japan & 563 & 483 & $\mathrm{p}<0.005$ & $1 \cdot 17$ \\
\hline WEIGHTED AVERAGE & 293 & 227 & - & 1.29 \\
\hline
\end{tabular}

"Significance of difference

Table 5 Sex differences in age-adjusted incidence rates for cerebrovascular disease (in 100000 a year) from different hospital-based studies

\begin{tabular}{lcclll}
\hline Study & Male rate & Female rate & $S D^{*}$ & $\begin{array}{l}\text { Malel } \\
\text { Female }\end{array}$ \\
\hline Harlem, USA & 248 & 217 & - & 1.14 \\
Manitoba, Canada & 223 & 175 & $\mathrm{p}<0.00005$ & 1.27 \\
Frederiksberg, Denmark & & & & \\
$\quad$ 1940-53 & 83 & 73 & $\mathrm{p}<0.05$ & 1.14 \\
Jerusalem, Israel & 193 & 150 & $\mathrm{p}<0.00005$ & 1.29 \\
WEIGHTED AVERAGE 181 & 144 & - & 1.26 \\
\hline
\end{tabular}

-Significance of difference

Table 6 Sex differences in age-adjusted incidence rates for cerebral infarction (in 100000 a year) from different community-based studies

\begin{tabular}{|c|c|c|c|c|}
\hline Study & Male rate & Female rate & $S D^{* *}$ & $\begin{array}{l}\text { Malel } \\
\text { Female }\end{array}$ \\
\hline \multicolumn{5}{|l|}{ Rochester, USA } \\
\hline $1955-69$ & 248 & 147 & $\mathrm{p}<0.005$ & 1.69 \\
\hline Middlesex Co, USA & 133 & 130 & $p>0.05$ & 1.02 \\
\hline Framingham, USA & $108^{*}$ & $97^{*}$ & - & $1 \cdot 11$ \\
\hline Oxford, UK & 102 & 81 & $\mathrm{p}<0.05$ & $1 \cdot 23$ \\
\hline \multicolumn{5}{|l|}{ Frederiksberg, Denmarkº } \\
\hline $1971-72$ & 85 & 48 & $\mathrm{p}<0.01$ & $1 \cdot 79$ \\
\hline Tartu, USSR & 221 & 171 & $p<0.0005$ & $1 \cdot 29$ \\
\hline Hiroshima, Japan & 304 & 229 & $p<0.0005$ & $1 \cdot 33$ \\
\hline \multicolumn{5}{|c|}{ WEIGHTED AVERAGE } \\
\hline (except Framingham) & 210 & 144 & - & 1.46 \\
\hline
\end{tabular}

In Table 7 male and female incidence rates for intracerebral haemorrhage are compared. In three of the five cases there is a male excess, and in two a female excess. None of the differences are significant.

In Table 8 male and female incidence rates for subarachnoid haemorrhage are compared. Both studies show a male age-adjusted rate which is $52 \%$ of the female rate. The difference is significant in one of the comparisons.

\section{Discussion}

The variation in the rates in Table 1 is wide, partly because of significant differences in factors other than age, such as the sex and racial composition of the study population, geographical location, and the years in which the study occurred. Alternatively, as Kurtzke $^{36}$ suggests, the wide variation may be due to statistical causes, including differences in disease definitions as well as methods of case ascertainment and confirmation of diagnosis. By tabulating the confidence limits, an attempt is made to quantify the effect of random fluctuations arising from the small size of numbers of cases reported, relative to the number of persons exposed to the risk of incidence.

Examples of the inherent technical differences between studies can be given by comparing the Evans County ${ }^{4}$ and Rochester ${ }^{2}$ investigations. In the former, the diagnostic criteria could be questioned, particularly as necropsy confirmation is largely absent. The latter investigation is based on the records of the Mayo Clinic. These records are among the most accurate available because the population of

Table 7 Sex differences in age-adjusted incidence rates for intracerebral haemorrhage (in 100000 a year) from different community-based studies

\begin{tabular}{lrlll}
\hline Study & Male rate & Female rate & $S D^{*}$ & $\begin{array}{l}\text { Malel } \\
\text { Female }\end{array}$ \\
\hline Rochester, USA & 24 & 17 & - & 1.37 \\
Middlesex Co, USA & 103 & 94 & $\mathrm{p}>0.05$ & 1.10 \\
Oxford, UK & 70 & 83 & $\mathrm{p}>0.05$ & 0.85 \\
Frederiksberg, Denmark & & & & \\
$\quad$ 1971-72 & 27 & 23 & $\mathrm{p}>0.05$ & 1.18 \\
Hiroshima, Japan & 16 & 17 & $\mathrm{p}>0.05$ & 0.94 \\
\hline
\end{tabular}

-Significance of difference

Table 8 Sex differences in age-adjusted incidence rates for subarachnoid haemorrhage (in 100000 a year) from different community-based studies

\begin{tabular}{lllll}
\hline Study & Male rate & Female rate & $S D^{*}$ & $\begin{array}{l}\text { Male/ } \\
\text { Female }\end{array}$ \\
\hline Oxford, UK & 11 & 22 & $\mathrm{p}<0.05$ & 0.52 \\
Hiroshima, Japan & 1.7 & 3.2 & $\mathrm{p}>0.05$ & 0.52 \\
\hline
\end{tabular}

*Significance of difference 
Rochester is, in medical terms, unique: the Mayo Clinic provides all medical services, and the studies have been continuing for several decades; in addition, a high quality index and retrieval system has been operative there for many years. ${ }^{37}$

As a further example, we note that the study design of the Oxford investigation ${ }^{9}$ was unusual. The study included all cases with cerebrovascular disease who had spent at least one night in hospital during the investigation period and all persons not admitted to hospital for whom the death certificate gave the underlying cause of death as cerebrovascular disease. It thus excluded those cases of stroke treated at home who either survived their first year of follow-up or died within one year from another underlying cause. It was argued by the authors that such an approach saved time and expense without much loss of accuracy. However, as pointed out by Cochrane, ${ }^{38} 39$ such an approach could involve an understatement of up to $45 \%$ in the incidence rates derived. We would therefore expect age-adjusted incidence rates calculated for this study as in Tables $1,3,4$, and 6 to be underestimates.

It seems reasonable to assume that technical differences between the studies such as those described above will affect the two sexes to the same extent, so that the data available are of epidemiological value for the purpose of elucidating the sex differences in incidence of cerebrovascular disease.

Apart from the Hiroshima study, ${ }^{16}$ most of the other age-adjusted incidence rates in Table 1 fall within the range $200-350$ per 100000 a year. The high levels of incidence shown for $\mathrm{Japan}^{16}$ and Finland ${ }^{14}$ are consistent with the high levels of causespecific mortality rates ascribed to cerebrovascular disease in those countries.

Further, because of the Atomic Bomb Casualty Commission's basic responsibilities, the Hiroshima population ${ }^{16}$ was carefully defined and the necropsy rate among fatalities was in excess of $70 \%$.

Despite the likelihood of wide variation in patient selection procedures and rates of completeness of identification of cases for hospital-based studies, the age-adjusted rates in Table 2 fall within the range 150-230 per 100000 a year, with one exception. The rate for Frederiksberg ${ }^{21}$ is very low, but a later community-based study in the same city ${ }^{12}$ reported an age-adjusted rate of 180 (Table 1).

The results in Table 3 also show a wide variation between studies. An important factor affecting these age-adjusted rates is the ability to effect an accurate differential diagnosis, in particular between cerebral infarction and cerebral haemorrhage. Those studies with low incidence rates for cerebral infarction ${ }^{39}$ have reported relatively high incidence rates for other pathologies, as illustrated in Tables 7 and 8 . The data for the Framingham study ${ }^{23}$ is anomalous in that only ages under 85 are included.

The patient selection and lack of complete ascertainment of cases in hospital-based studies is unlikely to affect the two sexes differently, so that the results of Tables 4 and 5 may be combined. In this situation, nine of the 16 possible sex differences in age-adjusted incidence rates were significant $(p<0.05)$. These results are inconclusive but seem to suggest that the male age-adjusted incidence rate is about $30 \%$ higher than the rate for females. Thus the weighted average rates in Tables 4 and 5 show a strikingly similar male excess incidence of about $30 \%$.

The results in Table 6 for cerebral infarction only are more striking. Five of the possible six sex differences are significant, which suggests that the male age-adjusted incidence rate is significantly higher than that for females. The weighted average figures suggest that the male excess is about $46 \%$, which is higher than that reported for all the pathologies combined.

The results in Table 7 for intracerebral haemorrhage indicate only a negligible difference between the two sexes. The results for subarachnoid haemorrhage in Table 8 indicate that the male ageadjusted incidence rate is about $50 \%$ of the female age-adjusted rate.

The hospital-based studies of Melamed $e t a^{22}$ and Abu-Zeid et al ${ }^{19}$ support these conclusions for intracerebral haemorrhage, neither finding significant differences between the sexes.

The consistency of the results described in Tables 4-8 may be shown by using the findings of the epidemiology study group ${ }^{28}$ who estimated the frequency distribution of new strokes for either sex by diagnostic type to be:

$$
\begin{array}{ll}
\text { Subarachnoid haemorrhage } & 10 \% \\
\text { Intracerebral haemorrhage } & 15 \% \\
\text { Cerebral infarction } & 75 \%
\end{array}
$$

Using these proportions as weights, and the results from Tables 6-8, we estimate the sex ratio for all new strokes to be:

$$
0 \cdot 10 \times 0 \cdot 52+0 \cdot 15 \times 1 \cdot 00+0 \cdot 75 \times 1 \cdot 46=1.30
$$

which agrees with the aggregate results for Tables 4 and 5 quoted above.

Reprints from Mr. S. Haberman, Actuarial Science Unit, The City University, Northampton Square, London EC1V 0HB. 


\section{Appendix}

(1) Consider two populations denoted by A and B with age-specific incidence rates given respectively by $\mathrm{q}_{\mathrm{X}}^{\mathrm{A}}$ and $\mathrm{q}_{\mathrm{X}}^{\mathrm{B}}$. Let $\mathrm{N}_{X}$ denote the age structure of the standard population (that is, the number of persons aged $x$ to $x+1$ ) and let $N$ denote the total size of the standard population. Then the age-adjusted incidence rates $\mathrm{q}^{\mathrm{A}}$ and $\mathrm{q}^{\mathrm{B}}$ are given by:

$$
q^{A}=\Sigma \frac{N_{x}}{N} \quad q^{B}=\Sigma \frac{N_{x}}{N} q_{X}^{B}
$$

For population $A$, let $i_{X}^{A}$ denote the number of incidence cases between ages $x$ and $x+1$, and let $n \hat{x}$ denote the number of population $A$ aged between $x$ and $x+1$ and exposed to the risk of incidence. Then:

$$
q_{1}^{A}=\frac{i_{x}^{A}}{n_{x}^{A}}
$$

and approximate $95 \%$ confidence limits for $\mathrm{q}^{\mathrm{A}}$ are given by:

$$
q^{A} \pm 1.96 \mathrm{se}\left(q^{A}\right)
$$

where

$$
\operatorname{se}\left(q^{A}\right)=\sqrt{\left(\frac{N_{x}}{N}\right)^{2} \frac{i_{x}^{A}}{\left(n_{x}^{A}\right)^{2}}}
$$

We have assumed that the number of incident cases in each age group follows a Poisson distribution, which is independent of the number of cases in the other age groups.

(2) For testing the significance of the difference $\mathrm{d}=\mathrm{q}^{\mathrm{A}}-\mathrm{q}^{\mathrm{B}}$ we compute $\mathrm{se}(\mathrm{d})$ and consider $\mathrm{z}=\mathrm{d} / \mathrm{se}(\mathrm{d})$ which may be shown to follow approximately the standard normal distribution.

Here $\operatorname{se}(d)=$

$$
\sqrt{\Sigma\left(\frac{N_{x}}{N}\right)^{2} \frac{\left(n_{x}^{A}+n_{x}^{B}\right)}{n_{i}^{A} n_{i}^{B}} \quad q_{x}^{o}\left(1-q_{\lambda}^{o}\right)}
$$

where $q_{X}^{O}$ is the pooled incidence rate: $\frac{i_{x}^{A}+i_{x}^{B}}{n_{x}^{A}+n_{x}^{B}}$

Since $q_{x}^{O} \ll 1$, we use the following approximation:

$$
\operatorname{se}(d)=\sqrt{\Sigma\left(\frac{N_{x}}{N}\right)^{2} \frac{\left(i_{x}^{A}+i_{x}^{B}\right)}{n_{x}^{A} n_{x}^{B}}}
$$

\section{References}

${ }^{1}$ Whisnant JP, Fitzgibbons JP, Kurland LT, Sayre GP. Natural history of stroke in Rochester, Minnesota, 1945 through 1954. Stroke 1971; 2: 11-22.

${ }^{2}$ Matsumoto N, Whisnant JP, Kurland LT, Okazaki H. Natural history of stroke in Rochester, Minnesota, 1955 through 1969: an extension of a previous study 1945 through 1954. Stroke 1973; 4: $20-9$.

${ }^{3}$ Eisenberg H, Morrison JT, Sullivan P, Foote FM. Cerebrovascular accidents: incidence and survival rates in a defined population, Middlesex County, Connecticut. JAMA 1968; 189: 883-8.

${ }^{4}$ Heyman A, Karp HR, Heyden S, Bartel A, Cassel JC, Tyroler HA, Hames CG. Cerebrovascular disease in the biracial population of Evans County, Georgia. Arch Intern Med 1971; 128: 949-55.

${ }^{5}$ Alter M, Christoferson L, Resch J, Myers G, Ford J. Cerebrovascular disease: frequency and population selectivity in an upper midwestern community. Stroke 1970; 1: 454-65.

'Parrish HM, Payne GH, Allen WC, Goldner JC, Sauer HI. Mid-Missouri stroke survey: a preliminary report. Mo Med 1966; 63: 816-21.

${ }^{7}$ Eckstrom PT, Brand FR, Edlavitch SA, Parrish HM. Epidemiology of stroke in a rural area: second year of the Mid-Missouri survey. Public Health Rep 1969; 84: 878-82.

${ }^{8}$ Carpenter RR, Rogers KD, Reed DE. Use of medical facilities in cerebrovascular disease patients in a county of West Pennsylvania. Stroke 1972; 3: 759-63.

${ }^{9}$ Acheson RM, Fairbairn AS. Burden of cerebrovascular disease in the Oxford area in 1963 and 1964. Br Med J 1970; ii: 621-6.

${ }^{10}$ Weddell JM. The Application of a Stroke Register For Planning. In: Rose FC, ed. Clinical Neuroepidemiology. Tunbridge Wells: Pitman Medical, 1980: 112-30.

${ }^{11}$ Chin PL, Angunawela R, Mitchell D, Horne J. Stroke Register-Carlisle: A Preliminary Report. In: Rose FC, ed. Clinical Neuroepidemiology. Tunbridge Wells: Pitman Medical, 1980: 131-43.

${ }^{12}$ Hansen BH and Marquardsen J. Incidence of stroke in Fredriksberg, Denmark. Stroke 1977; 8, 663-5.

${ }^{13}$ Medico-Social Research Board. Annual Report. Dublin: Cahill, 1975: 39-42.

${ }^{14} \mathrm{Aho} \mathrm{K}$, Fogelholm R. Incidence and early prognosis of stroke in Finland, 1972. Stroke 1974; 5, 658-62.

${ }^{15}$ Zupping R, Roose M. Epidemiology of cerebrovascular disease in Tartu, Estonia, USSR, 1970 through 1973. Stroke 1976; 7, 187-90.

${ }^{16}$ Johnson KG, Yamo K, Kato H. Cerebrovascular disease in Hiroshima, Japan. J Chronic Dis 1967; 20, 545-59.

${ }^{17}$ Bruun B, Richter RW. The epidemiology of stroke in Central Harlem. Stroke 1973; 4: 406-8.

${ }^{18}$ Gibson C. Epidemiology and patterns of care of stroke patients. Arch Phys Med Rehabil 1974; 55: 398-403.

${ }^{19}$ Abu-Zeid HAH, Choi NW, Nelson NA. Epidemiologic features of cerebrovascular disease in Manitoba: incidence by age, sex and residence with aetiologic implications. Can Med Assoc J 1975; 113: 379-84.

${ }^{20}$ Brewis M, Poskanzer DC, Rolland C, Miller $\mathrm{H}$. Neurological disease in an English city. Acta Neurol Scand 1966; 42, suppl 24: 1-89.

${ }^{21}$ Dalsgaard Nielsen T. Survey of 1000 cases of apoplexia cerebri. Acta Psychiatr Neurol Scand 1955; 30: 169-85.

${ }^{22}$ Melamed E, Cahane E, Carmon A, Lavy S. Stroke in Jerusalem District 1960 through 1967: an epidemiological study. Stroke 1973; 4: 465-71.

${ }^{23}$ Wolf PA, Kannel WB, Dawber TR. Prospective investigations: the Framingham Study and the 
epidemiology of stroke. In: Schoenberg BS, ed. Advances in Neurology, Volume 19. Neurological Epidemiology: Principles and Clinical Applications. New York: Raven Press, 1978: 107-20.

${ }^{24}$ Katsuki S, Hirota Y. Current concept of the frequency of cerebral haemorrhage and cerebral infarction in Japan. In: Siekert RG, Whisnant JP, ed. Cerebral Vascular Diseases. Transactions of the Fifth Conference. New York: Grune and Stratton, 1966.

${ }^{25}$ Peacock PB, Riley CP, Lampton TD, Ruffel SS, Walker JS. The Birmingham Stroke, Epidemiology and Rehabilitation Study. In: Stewart GT, Thomas CC, ed. Trends in Epidemiology Application to Health Service Research and Training. Illinois: Springfield, 1972: 231-345.

${ }^{26}$ Marquardsen J. An epidemiologic study of stroke in a Danish urban community. In: Gillingham F, Maudsley C, Williams A, ed. Edinburgh: Churchill Livingstone, 1976: 62-71.

${ }^{27}$ Furlan AJ, Whisnant JP, Elveback LR. The decreasing incidence of primary intracerebral haemorrhage: a population study. Ann Neurol 1979; 5: 367-73.

${ }^{28}$ Stallones RA, Dyken ML, Fang HCH, Heyman A, Seltser R, Stamler J. Epidemiology for stroke facilities planning. Stroke 1972; 3: 360-71.

${ }^{29}$ Kurtzke J. (1976). An Introduction to The Epidemiology of Cerebrovascular Disease. In: Scheinberg P, ed. Cerebrovascular Diseases. New York: Raven Press, 1976: 239-53.
${ }^{30}$ Haberman S, Capildeo R, Rose FC. Sex differences in stroke. In: Greenhalgh RM, ed. Hormones and Vascular Disease. Tunbridge Wells: Pitman Medical, 1981.

${ }^{31}$ Registrar General. Statistical Review for England and Wales. Part 1A, Medical. London: HMSO, 1973.

${ }^{32}$ Lew E. Biostatistical pitfalls in studies of arteriosclerotic heart disease. Fed Proc 1962; 21, suppl 11: 62-70.

${ }^{33}$ Armitage P. Statistical Methods in Medical Research. Oxford: Blackwell Scientific Publications, 1971: chapter 12 .

${ }^{34}$ Cochran WG. Some methods for strengthening the common $\mathrm{X}^{2}$ tests. Biometrics 1954; 10: 417-51.

${ }^{35}$ Yerushalmy $\mathrm{J}$. A mortality index for use in place of the age-adjusted death rates. Am J Public Health 1950; 41: 907-22.

${ }^{36}$ Kurtzke J. The Epidemiology of Cerebrovascular Diseases. New York: Springer Verlag, 1969.

${ }^{37}$ Kurland LT, Brian DD. (1978). Contributions to neurology from records linkage in Olmsted County, Minnesota. In: Schoenberg BS, ed. Advances in Neurology, Volume 19. Neurological Epidemiology: Principles and Clinical Applications. New York: Raven Press, 1978: 93-105.

${ }^{38}$ Cochrane AL. The burden of cerebrovascular disease. $\mathrm{Br}$ Med J 1970; iii: 165.

${ }^{39}$ Cochrane AL. The burden of cerebrovascular disease. $\mathrm{Br}$ Med J 1970; iii: 347. 